\title{
Electrogastrography: Methodology, Validation and Applications
}

\author{
Jieyun Yin* and Jiande D Z Chen \\ Division of Gastroenterology, University of Texas Medical Branch, Galveston, Texas, USA; and Ningbo Pace Translational Medical Research \\ Center, Beilun, Ningbo, China
}

Electrogastrography (EGG) is a non-invasive method for the measurement of gastric myoelectrical activity. It was first discovered in 1921 and popularized in 1990s. EGG is attractive because it is non-invasive. However, due to its non-invasive nature, there have also been controversies regarding validity and applications of EGG. The aim of this review is to discuss the methodologies, validation and applications of EGG. Pros and cons of EGG will also be discussed in detail. First, the gastric slow wave and its correlation with gastric motility are presented. The association between gastric dysrhythmia and impaired gastric motility is reviewed. Secondly the method for recording the electrogastrogram is presented in detail and pitfalls in the recording and analysis of EGG are discussed. Thirdly, findings reported in the literature demonstrating the accuracy of EGG in recording gastric slow waves and gastric dysrhythmia are reviewed and discussed. The correlation of the electrogastrogram with gastric contraction is carefully discussed. Finally, applications of EGG in a few major areas are reviewed.

\section{(J Neurogastroenterol Motil 2013;19:5-17)}

Key Words

Electrogastrography; Gastric slow waves; Gastrointestinal motility

\section{Introduction}

Electrogastrography is a non-invasive technique for recording gastric myoelectrical activity using cutaneous electrodes placed on the abdominal skin over the stomach. The surface recording obtained using electrography is called the electrogastrogram. In this review, both electrogastrography and electrogastrogram are abbreviated to EGG: "EGG" refers to the electrogastrography (the technique of recording the electrogastrogram) and "the EGG" refers to the electrogastrogram (the recording).
The EGG was first introduced in 1922 by Alvarez, ${ }^{1}$ rediscovered by Davis et $\mathrm{al}^{2}$ in 1957 and popularized in 1990s. ${ }^{3}$ Due to its non-invasive nature, EGG has received substantial attention among researchers and clinicians and also the controversies and concerns arosed. Some researchers use the EGG as a non-invasive measure of gastric slow waves and even consider it as a surrogate of gastric motility, whereas, others claim the EGG is flawed or even merely an artifact of gastric motions. In this article we will review available information in the literature and try to give readers an objective assessment of this non-invasive technique in detecting gastric slow waves.

Received: August 21, 2012 Revised: November 17, 2012 Accepted: November 19, 2012

(c) This is an Open Access article distributed under the terms of the Creative Commons Attribution Non-Commercial License (http://creativecommons. org/licenses/by-nc/3.0) which permits unrestricted non-commercial use, distribution, and reproduction in any medium, provided the original work is properly cited.

${ }^{*}$ Correspondence: Jieyun Yin, MD

GI Research Route 0655, 301 University Blvd., Galveston, Texas 77555, USA

Tel: +1-409-747-3071, Fax: +1-409-747-3084, E-mail: jiyin@utmb.edu

Financial support: None.

Conflicts of interest: None.

Author contributions: Jieyun Yin was responsible for collecting the data and drafting the manuscript. Jiande D Z Chen was responsible for revising the manuscript. 
To judge whether EGG is useful as a research and/or clinical tool, one needs to first understand completely what can be measured by EGG and how the EGG should be recorded and interpreted. Although it was unclear before 1960s whether the EGG was a recording of gastric myoelectrical activity or contractile activity, it is now clear that the EGG is a measurement of gastric slow waves. We will first review electrophysiology of the stomach, that is, gastric myoelectrical activity that can be measured using internal electrodes implanted on gastric serosa.

Secondly, we will provide technical details on how to measure the EGG. Since the EGG is a non-invasive measure using abdominal skin electrodes, it is sensitive to motion artifacts and electrical interferences from other internal organs. Therefore, it is critically important to measure the EGG appropriately and accurately. Detailed information will be provided on how to prepare the abdominal skin, where to place electrodes, how to choose filtering range (extremely important) and how to avoid and minimize motion artifacts.

Recently, some researchers have suggested that the EGG or any extracellular recordings of the stomach might be a mere measure of stomach movement artifact or contractile artifact. ${ }^{4}$ To answer this question, we will review numerous findings published in the literature as well as from our own labs regarding the validity of EGG. Data will be reviewed in 3 categories: (1) the relationship between the internal extracellular myoelectrical recording and gastric contractions: this will tell whether the internal extracellular myoelectrical recording is a measurement of true gastric myoelectrical activity or just an artifact of gastric contractions, (2) the relationship between the EGG and the internal serosal recording of the gastric slow wave: this will determine whether the EGG is an accurate measurement of gastric slow waves, and (3) the relationship between the EGG and gastric contractions. We believe that by reviewing these materials, the reader will be capable of determining whether the EGG is a measurement of gastric slow waves or just gastric contractile artifacts.

Last but not least, we will review applications of EGG, including the application of EGG for the study of gastric electrophysiology, the use of EGG in assessing the effect of an intervention and the clinical relevance of EGG in patients with symptoms suggestive of functional gastric dysmotility.

\section{Gastric Myoelectrical Activity}

\section{Normal Gastric Myoelectrical Activity}

Like in the heart, there is myoelectrical activity along the gut. Myoelectrical activity of the stomach consists of slow waves and spike potentials. The slow wave is also called pacesetter potential, or electrical control activity, whereas, spike potentials are referred to as action potentials or electrical response activity. ${ }^{5,6}$ The frequency of normal gastric slow waves is species-dependent, being approximately 3 cycles per minute (cpm) in humans ${ }^{7-9}$ and $5 \mathrm{cpm}$ in dogs. ${ }^{10,11}$ The gastric slow wave determines the maximum frequency and propagation of gastric contractions. Figure 1A presents normal gastric slow waves measured from a dog using internal electrodes permanently implanted on gastric serosa. Distallypropagated slow waves at a frequency of about $5 \mathrm{cpm}$ are clearly noted.

Spike potentials are considered as electrical counterparts of gastric contractions, i.e., a gastric contraction occurs when the slow wave is accompanied with spike potentials. We would like to point out, however, in the most part of the stomach, especially in the fundus and proximal antrum, a one-to-one correlation between spike potentials and gastric contractions is not commonly seen. It is not uncommon to record gastric contractions at the absence of spike potentials in the stomach. ${ }^{12}$

\section{Gastric Dysrhythmia and Abnormal Slow Waves}

Gastric myoelectrical activity may be altered or become abnormal in diseased states or upon provocative stimulations or even spontaneously. Abnormal gastric myoelectrical activity includes gastric dysrhythmia, abnormal slow wave propagation and electro-mechanical uncoupling. ${ }^{3,7,13}$

Gastric dysrhythmias can be further classified into bradygastria, tachygastria and arrhythmia. ${ }^{3,14-16}$ From internal serosal recordings, we know that the normal frequency of the gastric slow wave in humans is about $2-4 \mathrm{cpm}$, whereas bradygastria is in the range of 0.5-2.0 cpm and tachygastria in the range of 4-9 cpm. Tachygastria is usually ectopic and of an antral origin as shown in our lab. ${ }^{10}$ In more than $80 \%$ of cases, it is located in the antrum and propagates retrogradely. It may override completely the normal distally-propagated slow waves. However, in most cases, it does not completely override the normal gastric slow waves. In these cases, there are 2 pacemaking activities: a normal pacemaker in the proximal stomach and a tachygastrial pacemake in 
A

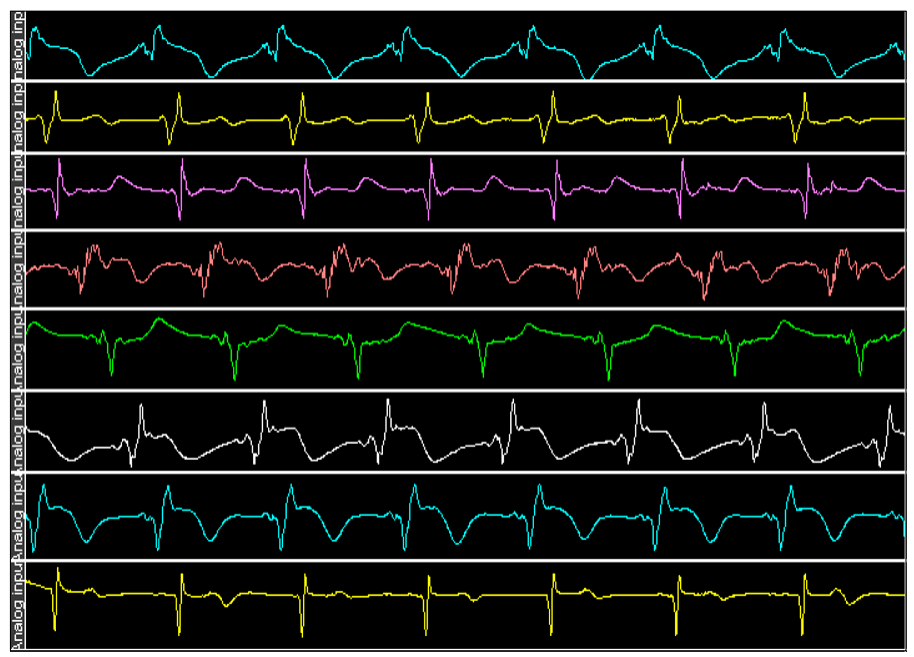

B

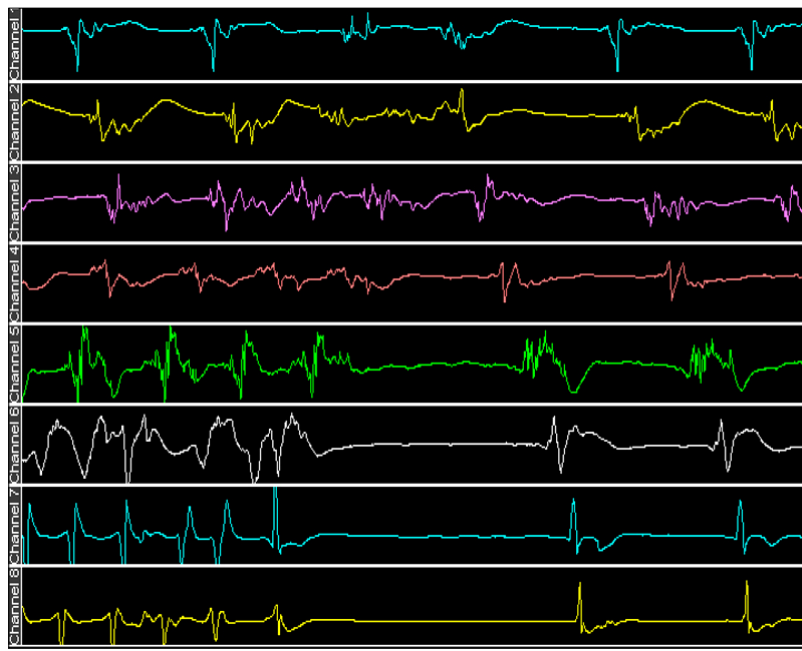

$12 \mathrm{sec}$

Figure 1. Gastric slow waves. Top to bottom tracing were obtained from serosal electrodes placed from proximal to distal stomach along the greater curvature with an interval of $2 \mathrm{~cm}$. (A) Normal gastric slow waves from a dog. (B) Spontaneous ectopic tachygastria in a dog.

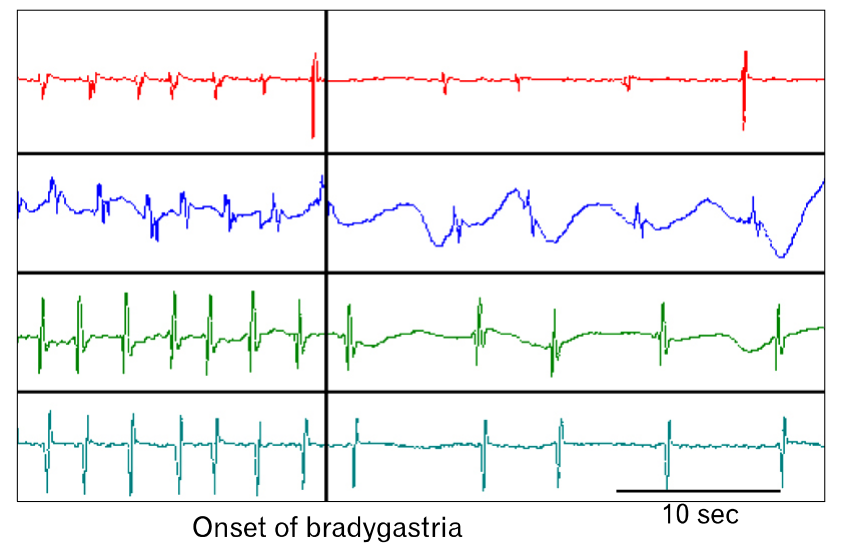

Figure 2. Bradygastria from serosal recordings in a dog. Both normal slow waves (left part) and bradygastria were initiated in the proximal stomach and propagated distally. Top to Bottom tracings: proximal to distal stomach at an interval of $4 \mathrm{~cm}$.

the distal stomach as shown in Figure 1. Different from tachygastria, bradygastria is not ectopic and reflects purely a reduction in frequency of the normal pacemaking activity as illustrated in Figure 2. It should be noted that distally propagated bradygastria may not have a significant impact on gastric contractions or emptying. ${ }^{3,10}$ Arrhythmia refers to the absence of rhythmic slow waves.

In addition to gastric dysrhythmia, abnormal slow wave propagation has recently been reported. In patients with gastro- paresis, abnormal slow wave propagation was detected by highresolution mapping, including abnormal slow wave initiation, reduced longitudinal propagation velocity and interruption of slow wave propagation. ${ }^{17}$

Electro-mechanical uncoupling refers to the presence of normal slow waves but absence of contractile activity. Myoelectrically, this could be the case of none of slow waves being superimposed on spike potentials. However, as stated earlier, in the stomach, there is lack of one-to-one correlation between spikes and contractions, and thus this abnormality cannot be accurately detected from the in vivo myoelectrical recording. ${ }^{12}$

\section{Correlation of Slow Waves With Gastric Co- ntractions}

To understand the correlation between gastric slow waves and contractions, we first must be aware how gastric slow waves and gastric contractions are recorded. Slow waves can be recorded intracellularly or extracellularly; the extracellular recording can be classified into in vitro and in vivo; the in vivo recording can be further classified into internal recording and abdominal surface recording, i.e., the EGG. It should be noted that the gastric slow wave measured using these different methods may have different physiological meanings and different clinical interpretations. Similarly gastric contractions can also be measured by different methods, including the use of strain gauges and manometry. ${ }^{6,14}$ Gastric manometry measures only lumen occluded con- 
A

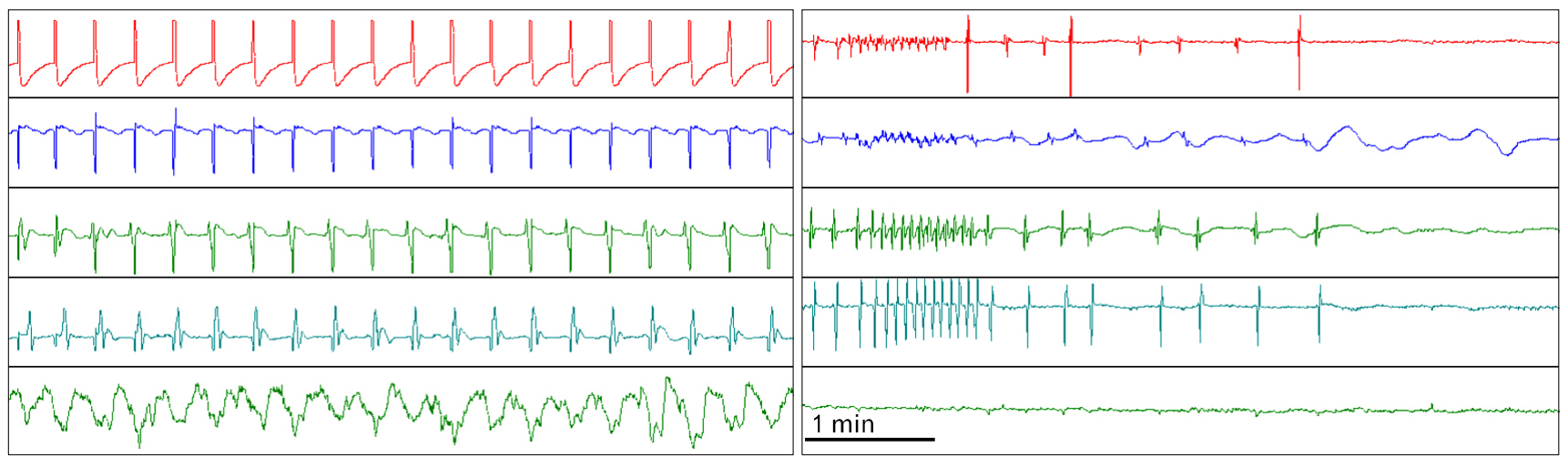

Fiğure 3. Correlation between slow waves and gastric contractions measured by strain gauges. Top 4 channel: serosal myoelectrical recordings from top to bottom ( $4 \mathrm{~cm}$ interval); bottom channel: gastric contractions measured from strain gauges placed on gastric serosa. (A) Normal slow waves and gastric contractions (one-to-one correlation). (B) Spontaneous gastric dysrhythmia and gastric hypomotility measured from the same strain gauges.

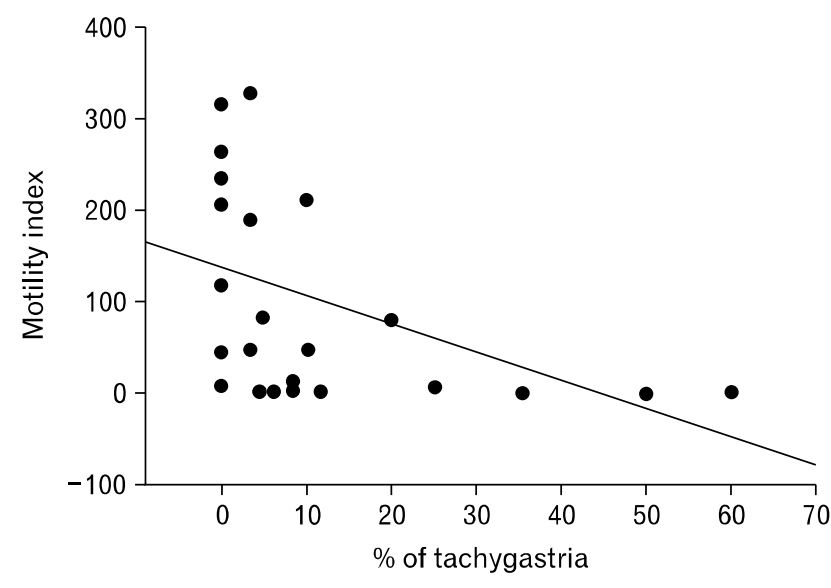

Figure 4. Correlation between gastric electrical stimulation inducing tachygastria and gastric hypomotility. The contractions was inversely correlated to the antral motility. When tachygastria was $25 \%$ or higher, gastric contractions were totally inhibited.

tractions via an intraluminal catheter placed in the stomach, a method commonly used in clinic, whereas the strain gauge is able to record both lumen occluded or non-occluded contractions, such as weak phasic tone of the stomach that is not typically detected by manometry.

Under normal/healthy conditions, a one-to-one correlation may be found between the in vivo gastric slow wave measured using internal serosal electrodes and gastric contractions measured by strain gauges. Figure $3 \mathrm{~A}$ presents such a correlation in a healthy dog. It can be seen that each gastric slow wave is accompanied with one gastric contraction. When gastric dysrhythmia occurs, gastric contractions disappear (Fig. 3B). From Figure $3 \mathrm{~B}$, we can also clearly observe that the slow waves recorded us- ing the in vivo extracellular method were not artifacts of gastric contractions: slow waves, although irregular, were present when there were not contractions at all. It should be noted that if gastric contractions are measured by manometry, such a one-to-one correlation between the slow waves and contractions cannot be detected.

To further investigate the correlation between tachygastria and gastric hypomotility and prove that the extracellular gastric recording is not an artifact of gastric contractions, we simultaneously recorded gastric myoelectrical recording using serosal electrodes and gastric contractions using strain gauge in a number of dogs, and performed electrical stimulation at a high frequency (2 times of the intrinsic frequency) to convert normal slow waves into tachygastria. As shown in Figure 4, normal slow waves and regular gastric contractions were present at baseline. Once electrical stimulation was initiated, gastric slow waves in the area adjacent to stimulation were turned into tachygastria and meanwhile, gastric contractions disappeared. Statistical analysis revealed that when tachygastria was present at more than $25 \%$ of time, antral contractions were completely inhibited. ${ }^{11}$ These findings also prove that the slow waves recorded by the internal serosal electrodes were not artifacts of gastric contractions.

\section{Electrogastrography: Measurement}

\section{Recording Setting}

Although this information is most commonly omitted in a biomedical research paper, appropriate setting of the recording equipment is critically important. Two major issues associated 
with an EGG recording device are: (1) amplification: the EGG signal is usually in a range of $50-500 \mu \mathrm{V}$ and adequate amplification needs to be provided by a recording device so that the amplified signal is of an appropriate range for display and analysis, and (2) filter setting: it determines the frequency range of the EGG signal to be maximally amplified. The interested range of the EGG signal is in the range of $0.5-9.0 \mathrm{cpm}$ or 0.0083 to $0.15 \mathrm{~Hz}$ which is much lower than that of most of extracellular recordings. In addition to the basic fundamental frequencies of 0.5-9.0 cpm, it is also important to record certain harmonics (multiples of the fundamental frequency). ${ }^{3,12}$ Accordingly, an appropriate frequency setting is in the range of 0.0083 to $1 \mathrm{~Hz} .{ }^{7,18,19}$ A wrong selection of filtering range may lead to a severe distortion or even disappearance of gastric slow waves in the EGG. Figure 5 illustrates such an example: with a frequency setting of 0.0083 to 1 $\mathrm{Hz}$, normal gastric slow waves were recorded in the EGG in a healthy subject (top tracing). When this same EGG signal was digitally filtered using a highpass filter at a frequency of $3 \mathrm{~Hz}$, gastric slow waves were no longer visible in the signal (bottom tracing). This example demonstrates the importance of filter setting while recording gastric slow waves. It should be noted that in most of recording apparatus used for intracellular or extracellular recordings, the filter is usually set to remove low frequency components of below $1 \mathrm{~Hz}$ or even higher in order to avoid baseline drift. That is, it is very likely that one is cannot record the gastric slow waves accurately if a recording device in use is not specifically designed for gastric slow waves.

\section{Procedure for Recording the Electrogastro- graphy}

One common mistake made in the EGG recording is the inadequate preparation of skin and placement of electrodes. Since the EGG signal is weak, it can be easily distorted or interfered by motion artifacts due to body movement and/or breathing. In order to accurately record an EGG, the following procedure should be strictly followed.

\section{Skin preparation}

First, the abdominal skin where the electrodes are to be positioned should be thoroughly cleaned to ensure that the impedance between the pair of electrodes is below $10 \mathrm{k} \Omega .^{20,21}$ To do so, it is advised to abrade the skin until it turns pinkish using some sandy skin-preparation jelly, and then apply a thin layer of electrode jelly for 1 minute for the jelly to penetrate into the skin. Before placing the electrode, the excessive jelly must be completely wiped out.

\section{Electrode placement}

Regular electrocardiogram (ECG) electrodes can be used for EGG recordings. The most commonly used configuration for recording 1-channel EGG is to place one electrode at the midpoint on a line connecting the xiphoid and umbilicus, and the other electrode $5 \mathrm{~cm}$ away (up and 45 degree) to the patient's left. The ground electrode is placed on the left costal margin horizontal to the first active electrode. ${ }^{22,23}$ If a 4-channel EGG recording device is used, multiple electrodes should be placed according to previous studies. $^{20,21}$ The multiple channel EGG may provide more information about slow wave propagation and coupling., ${ }^{8,24,25}$

B

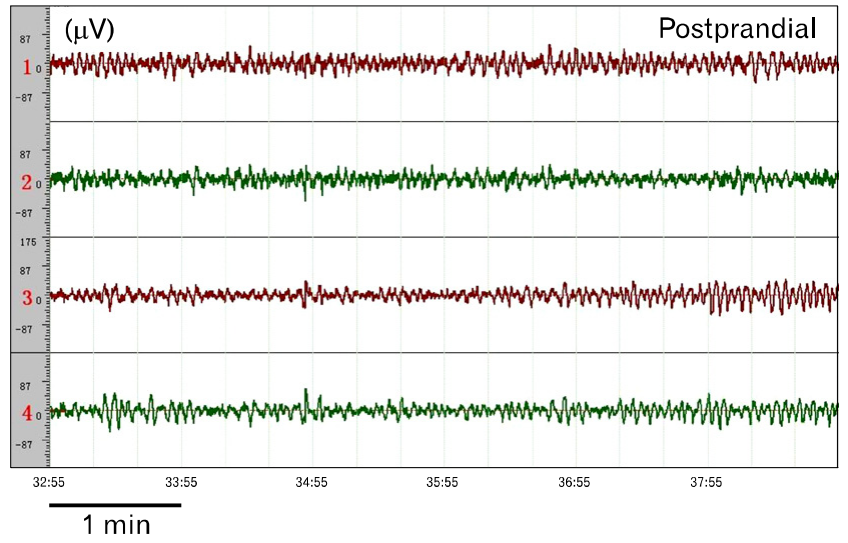

Figure 5. Effects of filtering. 4-channel electrogastrography (EGG) signals from a healthy subject after the meal. (A) Original tracings made by a 4-channel EGG device. (B) The signals in (A) filtered by a highpass filter with a cutoff frequency of $3 \mathrm{~Hz}$. Normal slow waves were seen before but not after digital filtering at $3 \mathrm{~Hz}$. 


\section{Subject position}

The most important points in positioning the subject are (1) to ensure that the subject is in a comfortable position, most commonly supine, so that body movement can be completely avoided or reduced to the minimal. The subject should be asked not to talk, move, read or make phone calls during the procedure ${ }^{14,26}$; and (2) to ensure that the position of the subject is the same if there are multiple sessions. Timing of unavoidable body movement or motion artifacts should be noted and the recording periods with motion artifacts must be removed before analysis.

\section{Duration of recording}

Another common mistake in recording the EGG is that the recording is too short. Unlike the ECG in which there are about 60 waves every minute, the EGG is composed of only 3 waves every minute. That is, if the recording is of a short duration of $5 \mathrm{mi}-$ nutes, there are only 15 waves which are obviously insufficient for analysis and interpretation. Ideally, at least a 30-minute period is needed to ensure an accurate measure of gastric slow waves in a particular state, such as fasting, fed, baseline or after intervention. $^{27}$

\section{Protocol for a clinical electrogastrography rest}

When EGG is used as a clinical test, the EGG should be recorded in both fasting and fed states. To ensure the stomach is empty when the baseline or fasting EGG is recorded, the subject should be fasted for at least 6 hours because the complete emptying of the stomach takes about 4 hours in a healthy subject and this can be longer if a patient has a suspected gastric motility disorders. Drinking (water) is not allowed at least 2 hours before the test. The duration of the postprandial recording should be at least 30-60 minutes, depending on the symptomatic response of the subject to meals. Similarly to other motility tests, any medications known to alter gastric motility should be discontinued for at least 2-3 days before the EGG test.

The test meal should contain a minimum of $250 \mathrm{kcal}$ (better $>400 \mathrm{kcal}$ ) with no more than $35 \%$ of fat. ${ }^{27}$ Solid meals are usually recommended although a few investigators have used water as the test "meal." ${ }^{28}$ It should be noted that different test meals may result in different postprandial EGG responses. Accordingly, when data are compared among different studies, the composition of the meal should be carefully examined. In healthy humans, a solid test meal with sufficiently high calories $(>400$ $\mathrm{kcal}$ ) results in an increase in both amplitude and frequency of gastric slow waves; a liquid meal may increase slow wave amplitude but reduce its frequency; a meal with a high percentage of fat ( $>50 \%$ ) may induce gastric dysrhythmia. ${ }^{29-32}$ Accordingly, the composition of the meal should be considered when interpreting postprandial EGG.

The study subject should be kept alert and should not fall asleep during the procedure as gastric slow waves have been reported to change during sleep. ${ }^{33}$

\section{Pitfalls in electrogastrography recording}

It is most important to note that an EGG study could be flawed or completely useless if any of the followings takes place: the skin is not appropriately prepared, the subject is engaged in conversation, the subject moves frequently and the periods with body movement are not deleted, or the recording for a particular condition is shorter than 15 minutes. Cautions should also be made in the analysis of the EGG recording described as follows. ${ }^{26}$

\section{Electrogastrogram: Analysis}

Unlike the electrocardiogram with which a physician can perform diagnosis by visually examining the tracing, the EGG must be subjected to computerized spectral analysis. This is because the EGG signal is weighted summation of all gastric slow waves presented in the stomach; its waveform is dependent on many uncontrollable factors and no diagnostic criteria have been established using the waveform of the EGG. In addition, the EGG also contains respiration artifact that is between $12-25 \mathrm{cpm}$ and sometimes the ECG artifacts ( $<60 \mathrm{cpm}$ ). Occasionally, the slow wave of the small intestine may also be recorded in the EGG (9-12 cpm). Although these interferences distort gastric slow waves in the EGG, their frequencies do not overlap with that of the gastric slow waves. Consequently, spectral analysis can be performed to separate the gastric slow waves from interferences. ${ }^{3}$ As stated earlier, before spectral analysis is performed, any periods with motion artifacts must be identified and deleted because motion artifacts can not be separated from the gastric slow waves even with spectral analysis.

Clinically established EGG parameters that can be extracted from the spectral analysis include dominant frequency and power, fasting-fed power ratio, percentage of normal gastric slow waves, percentage of gastric dysrhythmias, and percentage of power distribution described as follows. ${ }^{3,34-37}$

\section{Dominant Frequency and Power}

The dominant frequency and power of the EGG can be derived from the power spectral density assessed by the periodogram method (Fig. 6). ${ }^{38}$ The normal range of the dominant frequency of the EGG is between 2 to $4 \mathrm{cpm} .{ }^{39}$ The EGG is called 
A

EGG tracing

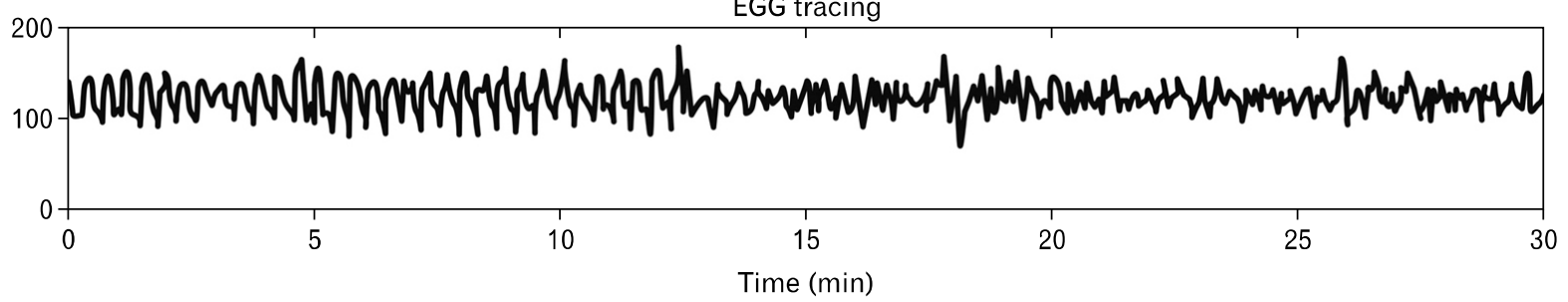

B

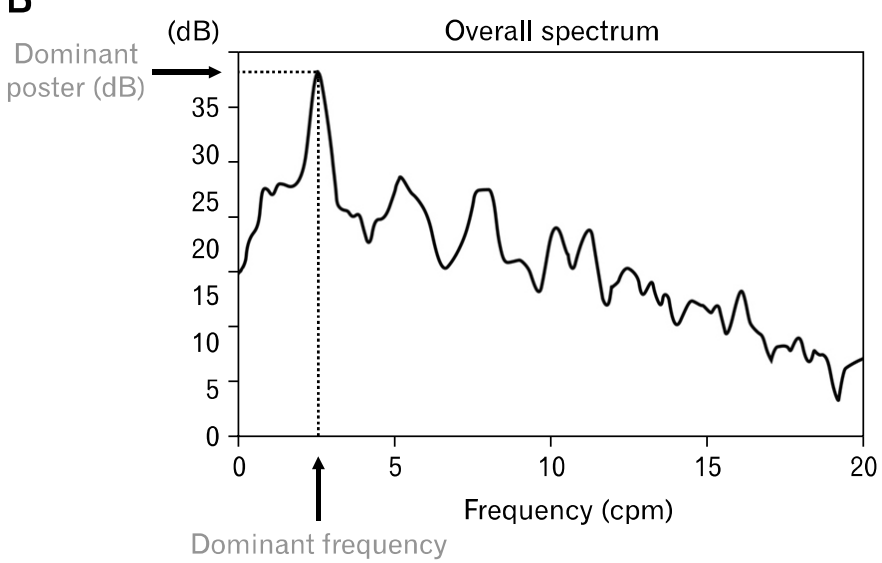

C

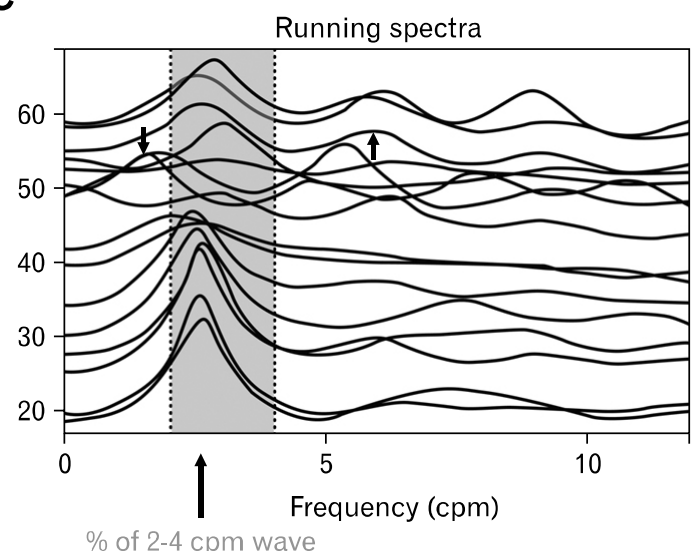

Figure 6. Spectral analyses of the electrogastrography (EGG). (A) Original EGG tracing. (B) Overall spectral analysis. (C) Adaptive running spectra.

bradygastria if its dominant frequency is lower than $2 \mathrm{cpm}$, tachygastria if its dominant frequency is higher than $4 \mathrm{cpm}$ but lower than $9 \mathrm{cpm}$, and arrhythmia if there is no dominant peak power in the spectrum.

\section{Power Ratio or Relative Electrogastrography Power Change}

The ratio of dominant EGG powers between after and before an intervention is a commonly used parameter that is associated with alteration in gastric contractions. It is generally accepted that a ratio of $>1$ reflects an increase in gastric contractility due to the intervention, whereas a ratio of $<1$ reflects a decrease in gastric contractility. ${ }^{3}$ If the decibel $(\mathrm{dB})$ unit is used, the ratio should be replaced by the difference between the baseline and after intervention.

\section{Percentage of Normal Gastric Slow Waves}

The percentage of normal slow waves is a quantitative assessment of the regularity of the gastric slow wave measured from the EGG. It is defined as the percentage of time during which normal gastric slow waves are observed in the EGG. The percentage of normal slow waves can be computed from the running power spectra of the EGG (Fig. 6). ${ }^{3,40}$ In this method, 1 spectrum is de- rived from every 1 minute (or some other short period) of EGG data; the minute is considered normal if its EGG spectrum exhibits a dominant power in the range of 2-4 cpm. In human, the normal percentage of gastric slow wave is defined as $70 \%$. $3,7,822,39$

\section{Percentage of Gastric Dysrhythmia}

The percentage of gastric dysrhythmia is defined as the percentage of time during which gastric dysrhythmia is observed in the EGG. It is computed in the same way as that for the percentage of normal slow waves. It is further classified into the percentage of bradygastria, the percentage of tachygastria and the percentage of arrhythmia.

\section{Percentage of Electrogastrography Power Dis- tribution}

The percentage of EGG power distribution was introduced by Koch et $\mathrm{al}^{29}$ and is defined as the percentage of total power in a specific frequency range in comparison with the power in the total frequency range from 1 to $15 \mathrm{cpm}$. For example: \% of (2.4-3.6 cpm) $=$ The power within 2.4-3.6 cpm/The total power from 1-15 cpm $\times 100 \%$.

The advantage of this method is that it is easy for computation. We should be aware, however, that only relative values 
of this parameters in comparison with the control data should be used. Even in normal subjects, the percentage of normal EGG activity computed in this way will never be $100 \%$. It should also be pointed out that this parameter is sensitive to noise, since any noise component in the frequency band of 1 to $15 \mathrm{cpm}$ affects the computation of this parameter. Harmonics of the fundamental 3 cpm slow wave may be computed as tachygastria. ${ }^{19,35}$

\section{Other Parameters}

Other parameters include instability coefficients of dominant frequency and dominant power. ${ }^{7,8}$ However, the clinical relevance of these parameters is not established. If the EGG is recorded with a 4-channel device, there are a number of other parameters, such as the percentage of slow wave coupling between any 2-channels and the propagation of slow waves. ${ }^{8,24}$

\section{Electrogastrography: Validation}

Due to its non-invasive nature as well as its vulnerability to noises and interferences, there have been concerns and controversies on validity of EGG. Based on our review of the literature, these concerns/controversies can be classified into 2 categories: (1) questions/concerns relevant to EGG and must be addressed, including (i) is the EGG an accurate measure of gastric slow waves? and (ii) is the EGG correlated or associated with gastric motility? Available data in the literature will be reviewed to discuss these issues; and (2) controversial findings obtained using inappropriate methods of EGG or methods different from EGG. For an example, in a recent article, the authors claimed that the EGG might be a measure of contraction artifacts while their findings were obtained from gastric tissues of patients with cancers using a device totally different from that used in EGG. ${ }^{4}$

\section{Correlation of the Electrogastrography With Internal Serosal Recording}

When appropriately recorded as discussed in the previous section, the EGG is an accurate measurement of gastric slow waves and the parameters derived from the spectral analysis of the EGG correlated with those determined from the internal serosal recordings. EGG recordings simultaneously made with the se$\operatorname{rosal}^{10,12,41}$ or mucosal ${ }^{16,42,43}$ recordings have proven that the dominant frequency of the EGG accurately represents the frequency of the gastric slow wave. Figure 7 presents such a typical example. It is clear that the frequencies of the gastric slow wave recorded by serosal and abdominal surface electrodes were ex- actly the same (see the fundamental frequency in the power spectrum [Fig. 7B]). However, it is typical that slow waves recorded in the serosal recording are more pulse-like (especially for those recorded from the antrum), whereas, those recorded in the EGG are more sinusoidal. This is because (1) the human abdominal wall acts like a lowpass filter that makes the signals more smooth and (2) inherently, the EGG is a weighted summation of all internal gastric slow waves. It can also be appreciated that the spectrum of the serosal recording consists of more harmonics than that of the EGG. In other studies, the EGG was validated by showing the presence of $3 \mathrm{cpm}$ waves at baseline and the disappearance of slow waves in the EGG after the removal of the entire stomach. ${ }^{44}$

\section{Correlation of the Electrogastrography With Gastric Motility}

A one-to-one correlation does not exist between the slow waves recorded in the EGG and gastric contractions measured by manometry because these two are different measurements: the EGG is a measure of overall slow waves from the stomach, whereas, the gastric manometry is a measure of gastric contractions at specific locations. However, several studies have shown correlations between the EGG and gastric contractile activities. $^{45-47}$ For example, in one clinical study with simultaneous EGG and gastric manometry, the EGG was found to exhibit an increased dominant power and reduced dominant frequency during motor activity, in comparison with those during motor quiescence. $^{45}$ Although contraction-related spike activities can not be recorded in the EGG, the relative increase in EGG dominant power has been repetitively and consistently shown to be associated with an increase in gastric contractile activity.

Similar to the internal serosal recording, gastric dysrhythmias have also been detected from the EGG and shown to be associated with gastric hypomotility or impaired gastric contractions. Excessive tachygastria was observed in the EGG in patients with gastric motility disorder. ${ }^{13}$ In 31 patients with functional dyspepsia (FD) and simultaneous recordings of the EGG and gastroduodenal manometry, $71 \%$ of the patients showed excessive gastric dysrhythmias ( $>30 \%$ of time) and $80 \%$ of the patients had abnormal antral contractions. Nineteen of the 31 patients showed both abnormal EGG and abnormal antral motility, whereas only 2 patients showed both normal EGG and normal antral motility. $^{48}$ 
A

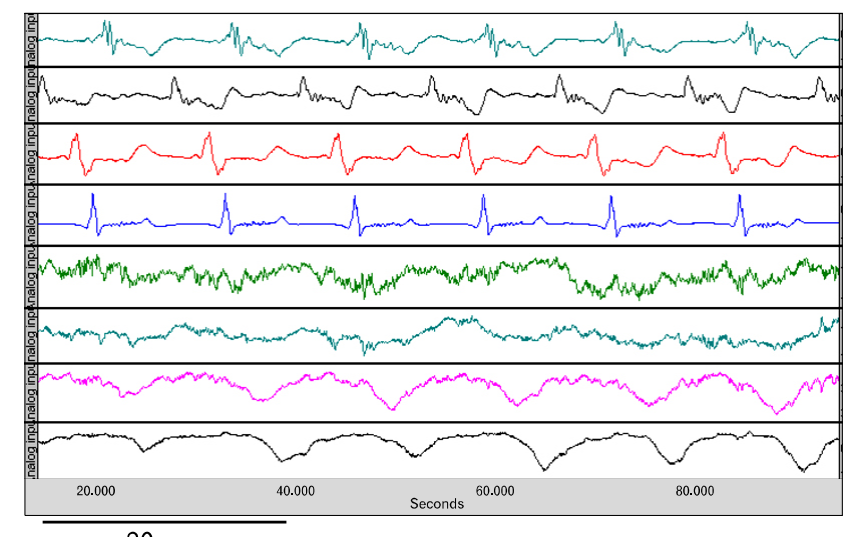

B

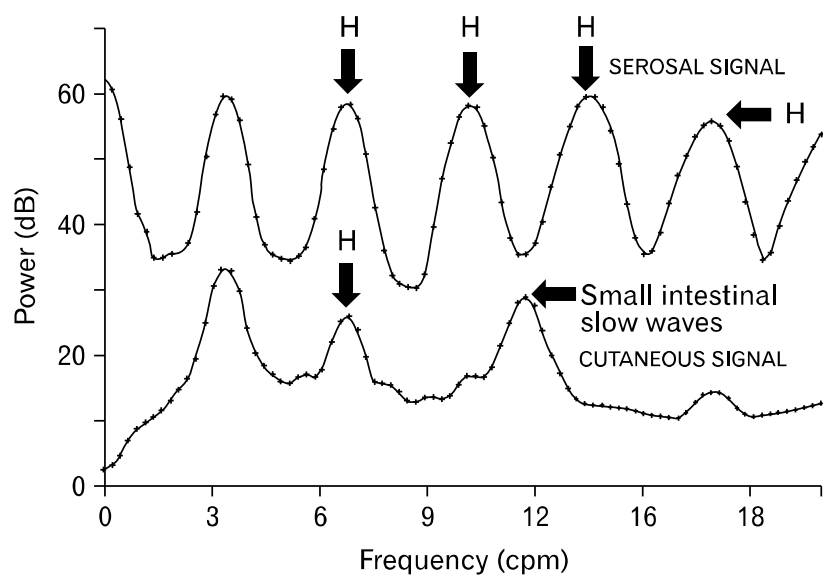

Figure 7. Correlation of the electrogastrography (EGG) with gastric slow waves measured by serosal electrodes. (A) Simultaneous recordings of gastric slow waves measured by internal serosal electrodes (top 4-channels) and abdominal surface electrodes (EGG, bottom 4-channels). (B) Power spectral of the serosal and cutaneous recordings. The third peak in the bottom power spectrum indicated the peak of intestinal slow waves. $\mathrm{H}$, harmonics.

\section{Correlation of the Electrogastrography With Gastric Emptying}

The correlation between the EGG and gastric emptying was reported in a number of studies. ${ }^{22,49,50}$ In patients with $\mathrm{FD}$, the EGG and gastric emptying scintigraphy were found to be complimentary for the assessment of dyspepsia. ${ }^{49}$ In pediatric patients with gastric esophageal reflux, the postprandial change in EGG dominant power was reported to significantly correlate with the rate of stomach emptying. ${ }^{50}$ In 157 patients with symptoms suggestive of gastroparesis and simultaneous recordings of the EGG and gastric emptying, we found that patients with delayed gastric emptying had a lower percentage of normal gastric slow waves detected from the EGG and a lower postprandial increase in EGG dominant power than those with normal gastric emptying. Moreover, delayed gastric emptying was able to be predicted using the EGG with a specificity of $80 \%$ and a sensitivity of $55-60 \%{ }^{22}$ Using pattern recognition or classification methods, a higher accuracy could be achieved in the prediction of delayed gastric emptying from the EGG. ${ }^{51}$

\section{Electrogastrography: Applications}

Applications of EGG have been reported in numerous studies and the list of applications is lengthy. In this review, we only summarize a few applications in the following areas: (1) electrophysiological studies, (2) assessment of the efficacy of an intervention or therapy, and (3) detection of slow wave abnormalities in patients with gastric motility disorders or suspected gastric mo-

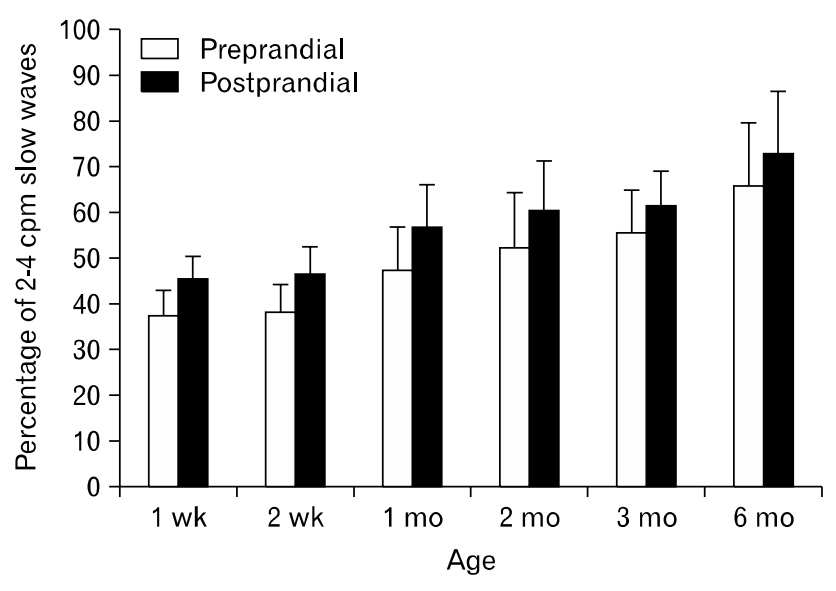

Figure 8. Development of gastric slow waves measured by electrogastrography in infants.

tility disorders.

\section{Electrophysiological Studies}

EGG is an attractive method for studying electrophysiology of the stomach since it is non-invasive and does not interrupt on-going process of the stomach. One such application is studying the developmental process of gastric slow waves in newborns. ${ }^{52}$ A progressive increase in the percentage of normal gastric slow waves was noted during the first 6 months after birth in 19 preterm infants. As it is shown in Figure 8, the percentage of normal slow waves in the fasting state was below $40 \%$ at one week after birth and became $65 \%$ at 6 months after birth.

In another study, the EGG was used to assess the effect of 
CNS on gastric slow waves. ${ }^{33} \mathrm{~A}$ significant reduction in slow wave amplitude, regularity and coupling was noted during non-rapid eye movement, suggesting the regulatory effect of CNS on gastric slow waves. 33,53

\section{Interventional Studies}

Similar to gastric motility, gastric slow waves may be affected by various interventions, such as stress and pharmacological therapies. EGG as a non-invasive tool has been frequently used in assessing the effect of stress and efficacy of pharmacological therapies, most commonly prokinetic therapies.

The relationship between motion sickness and gastric slow waves has been studied using EGG in a series of experiments. ${ }^{36,54}$ Tachygastia or tachyarrhythmia was frequently and consistently reported in the EGG in subjects with visually induced motion sickness. In a space flight, the non-invasive EGG revealed gastric dysrhythmias prior to nausea and vomiting and reduced postprandial dominant power on inflight day 1 that was returned to normal on inflight day 3 in 3 crewmembers. ${ }^{55}$

Gastric slow waves may be altered under stress, similar to gastrointestinal motility. Stern et $\mathrm{al}^{56}$ reported significantly decreased normal $3 \mathrm{cpm}$ activity in the EGG during cold stress in the fed but not during fasting state in healthy humans. Emotional stress induced by viewing a horror movie in healthy also inhibited normal postprandial responses to a test meal and induced gastric dysrhythmias in the EGG in both fasting and fed states in healthy volunteers with simultaneous inhibition of postprandial vagal activity. $^{9}$

Distention or retention of the distal part of gut is known to impair motility of the proximal part of gut. Similar inhibitory effects have also been reported with gastric slow waves measured by EGG. Gastric dysrhythmias assessed from the EGG were induced during rectal distension in the fed state in healthy volunteers $^{57}$; this inhibitory effect was found to be attributed to disturbed sympathovagal balance (increased sympathetic activity and reduced vagal tone due to distention) and was normalized with electroacupuncture at ST36 in both $\operatorname{dogs}^{58}$ and humans. ${ }^{59}$ Electroacupuncture has been consistently shown to improve gastrointestinal motility as well as gastric slow waves via its excitatory effect on vagal activity. ${ }^{60}$

Prokinetic agents are used for treating gastrointestinal dysmotility and have been reported to alter (mostly improve) gastric slow waves measured by EGG. Cisapride was reported to improve gastric dysrhythmias and dyspeptic symptoms in patients with FD, mostly in the postprandial state. ${ }^{61-64}$ EGG has also been used to assess the effect of other prokinetic agents, such as erythromycin, ${ }^{65-67}$ domperidone ${ }^{68-70}$ and tegaserod. ${ }^{71}$

\section{Gastrointestinal Motility Disorders}

In patients with gastrointestinal motility disorders or patients with functional gastrointestinal diseases, EGG is used to identify the pathophysiology of the diseases associated with gastric slow waves or dysrhythmia. EGG abnormalities have been most frequently reported in patients with gastroparesis. It is believed that about 50 to $75 \%$ of patients with gastroparesis have one or more abnormalities in the EGG. ${ }^{21,39,72,73}$ The abnormalities in EGG include reduced percentage of normal slow waves, excessive gastric dysrhythmia and decreased postprandial EGG dominant power. EGG has become a useful clinical tool in the diagnosis of gastroparesis and in understanding the pathogenesis of gastroparesis. Gastric dysrhythmia is also common in patients with unexplained nausea and vomiting and patients with early pregnancy although straight correlation between gastric dysrhythmia and nausea/vomiting has rarely been established. ${ }^{74-78}$

EGG was also used to investigate the correlations of gastric slow waves with gastric emptying and dyspeptic symptoms in gastroesophageal reflux disease (GERD) ${ }^{50,79,80}$ Gastric myoelectrical abnormalities assessed from the EGG have been frequently described in patients with FD. ${ }^{81-84}$ To assess the specificity of the EGG as well as the prevalence and pattern of abnormalities, Leahy et $\mathrm{al}^{85}$ performed EGG in 170 patients with $\mathrm{FD}, 70$ patients with irritable bowel syndrome (IBS), 20 patients with GERD, and 30 asymptomatic controls, reporting abnormal EGG in $36 \%$ of patients with FD and in $25 \%$ with IBS who complained of concurrent dyspepsia. The EGG was normal in $93 \%$ of asymptomatic controls, $90 \%$ of patients with GERD, and $92 \%$ of patients with IBS who did not complain of dyspepsia.

\section{Summary}

We have carefully reviewed relevant studies and their findings in the literature in an effort to answer a number of challenging questions, including whether EGG is a valid method, whether EGG provides useful information on gastric motility and whether EGG has meaningful clinical applications.

Is EGG a valid method? It all depends on how the EGG is recorded. If the EGG is made according to the procedure described in this review, it accurately records gastric slow waves and the parameters derived from the spectral analysis providing clinically and/or physiologically meaningful information. However, 
if the EGG is carelessly recorded and/or analyzed, it may not provide any meaningful information. This is similar to other clinical procedures; however, adherence to the exact procedure and protocol is extremely important in performing EGG. All pitfalls discussed in this review must be avoided.

Is the EGG a measure of gastric contractile artifacts? The answer is clearly "no." From findings presented in this review, we know clearly that the EGG is an accurate measure of gastric slow waves assessed from the in vivo serosal recording. The slow waves measured by the internal serosal electrodes are obviously not contractile artifacts as shown in Figure 3 in which one-to-one correlation was noted between the slow waves and contractions measured by strain gauge, whereas no contractions were noted when the slow waves became dysrhythmic.

Is the EGG a useful measurement of gastric motility? Yes or no. The EGG measures gastric slow waves and gastric slow waves are not gastric contractions. Since gastric slow waves determine frequency and propagation of antral contractions, and gastric dysrhythmia is associated with antral hypomotility, an accurate measurement of gastric slow waves by EGG does provide meaningful information about gastric motility. In a more general sense, gastric motility includes gastric slow waves, antral contractions and gastric emptying.

Is EGG a useful clinical diagnostic tool? It depends on the recording, analysis and interpretation of the EGG. If one considers the EGG as a measure of gastric contractions or gastric emptying, he/she may claim that the EGG is not a useful tool because the EGG measures slow waves, not contractions or emptying. If one is interested in exploring pathophysiologies associated with a disease, such as gastroparesis or FD, EGG is a useful diagnostic tool because it determines whether gastric slow waves are normal. In our opinion, accurate and non-invasive measure of gastric slow waves is clinically and physiologically meaningful. However, one should not consider the EGG as a measure of contractions or emptying.

\section{Conclusion}

The EGG is an accurate measure of gastric slow waves when it is recorded appropriately, and provides clinically, physiologically and/or pathophysiologically meaningful information when it is properly analyzed and interpreted.

\section{References}

1. Alvarez WC. The electrogastrogram and what it shows. JAMA 1922;78:1116-1119.

2. Davis RC, Carafolo L, Gault FP. An exploration of abdominal potentials. J Comp Psysiol Psycol 1957;50:519-523.

3. Chen JD, McCallum RW. Electrogastrographic parameters and their clinical significance. In: Chen JD, McCallum RW, eds. Electrogastrography: principles and applications. New York: Raven 1994:45-73.

4. Rhee PL, Lee JY, Son HJ, et al. Analysis of pacemaker activity in the human stomach. J Physiol 2011;589(Pt 24):6105-6118.

5. Sarna SK. Gastrointestinal electrical activity: terminology. Gastroenterology 1975;68:1631-1635.

6. Kelly KA. Motiltiy of the stomach and gastroduodenal junction. In: Johnson IA, ed. Physiology of the gastrointestinal tract. New York: Raven 1981:393-410.

7. Chen JD, McCallum RW. Clinical application of electrogastrography. Am J Gastroenterol 1993;88:1324-1336.

8. Lin X, Chen JZ. Abnormal gastric slow waves in patients with functional dyspepsia assessed by multichannel electrogastrography. Am J Physiol Gastrointest Liver Physiol 2001;280:G1370-G1375.

9. Yin J, Levanon D, Chen JD. Inhibitory effects of stress on postprandial gastric myoelectrical activity and vagal tone in healthy subjects. Neurogastroenterol Motil 2004;16:737-744.

10. Qian LW, Pasricha PJ, Chen JD. Origin and patterns of spontaneous and drug-induced canine gastric myoelectrical dysrhythmias. Dig Dis Sci 2003;48:508-515.

11. Ouyang H, Xing J, Chen JD. Tachygastria induced by gastric electrical stimulation is mediated via alpha- and beta-adrenergic pathway and inhibits antral motility in dogs. Neurogastroenterol Motil 2005; 17:846-853.

12. Chen J, Schirmer BD, McCallum EW. Serosal and cutaneous recordings of gastric myoelectrical activity in patients with gastroparesis. Am J Physiol 1994;266(1 Pt 1):G90-G98.

13. Chen JD, Pan J, McCallum RW. Clinical significance of gastric myoelectrical dysrhythmias. Dig Dis 1995;13:275-290.

14. Camilleri M, Hasler W, Parkman HP, Quigley EM, Soffer E. Measurement of gastroduodenal motility in the GI laboratory. Gastroenterology 1998;115:747-762.

15. Nelsen TS, Kohatsu S. Clinical electrogastrography and its relationship to gastric surgery. Am J Surg 1968;116:215-222.

16. Abell TL, Malagelada JR. Glucagon-evoked gastric dysrhythmias in humans shown by an improved electrogastrographic technique. Gastroenterology 1985;88:1932-1940.

17. O'Grady G, Angeli TR, Du P, et al. Abnormal initiation and conduction of slow-wave activity in gastroparesis, defined by high-resolution electrical mapping. Gastroenterology 2012;143:589-598. e1-e3.

18. Oppenheim AV, Schafer RW. Digital signal processing. Englewood Cliffs: Prentice Hall 1975:26-34.

19. Mintchev MP, Rashev PZ, Bowes KL. Misinterpretation of human electrogastrograms related to inappropriate data conditioning and acquisition using digital computers. Dig Dis Sci 2000;45:2137-2144.

20. Simonian HP, Panganamamula K, Parkman HP, et al. Multichan- 
nel electrogastrography (EGG) in normal subjects: a multicenter study. Dig Dis Sci 2004;49:594-601.

21. Simonian HP, Panganamamula K, Chen JZ, Fisher RS, Parkman HP. Multichannel electrogastrography (EGG) in symptomatic patients: a single center study. Am J Gastroenterol 2004;99:478-485.

22. Chen JDZ, Lin L, Pan J, McCallum RW. Abnormal gastric myoelectrical activity and delayed gastric emptying in patients with symptoms suggestive of gastroparesis. Dig Dis Sci 1996;41:15381545.

23. Patterson M, Rintala R, Lloyd D, Abernethy L, Houghton D, Williams J. Validation of electrode placement in neonatal electrogastrography. Dig Dis Sci 2001;40:2245-2249.

24. Chen JD, Zou X, Lin X, Ouyang S, Liang J. Detection of gastric slow wave propagation from the cutaneous electrogastrogram. Am J Physiol 1999;277:G424-G430.

25. McNearney T, Lin X, Shrestha J, Lisse J, Chen JD. Characterization of gastric myoelectrical rhythms in patients with systemic sclerosis using multichannel surface electrogastrography. Dig Dis Sci 2002;47:690-698.

26. Verhagen MA, Van Schelven LJ, Samsom M, Smout AJ. Pitfalls in the analysis of electrogastrographic recordings. Gastroenterololgy 1999;117;453-460.

27. Levanon D, Zhang M, Chen JD. Efficiency and efficacy of the electrogastrogram. Dig Dis Sci 1998;43:1023-1030.

28. Koch KL, Hong SP, Xu L. Reproducibility of gastric myoelectric activity and the water load test in patients with dysmotility-like dyspepsia symptoms and in control subjects. J Clin Gastroenterol 2000; 31:125-129.

29. Koch KL, Stewart WR, Stern RM. Effect of barium meals on gastric electromechanical activity in man. Dig Dis Sci 1987;32:1217-1222.

30. Chen J, McCallum RW. The response of electrical activity in normal human stomach to water and solid meal. Med Biol Eng Comput 1991;29:351-357.

31. Levanon D, Zhang M, Orr WC, Chen JDZ. Effects of meal volume and composition on gastric myoelectrical activity. Am J Physiol 1998;274(2 Pt 1):G430-G434.

32. Chen J, McCallum RW. Effect of milk on myoelectrical activity in normal human stomach - an electrogastrographic study. Med Biol Eng Comput 1992;30:564-567.

33. Orr WC, Crowell MD, Lin B, Harnish MJ, Chen JD. Sleep and gastric function in irritable bowel syndrome: derailing the brain-gut axis. Gut 1997;41:390-393.

34. Smout AJ, van der Schee EJ, Grashuis JL. What is measured in electrogastrography? Dig Dis Sci 1980;25:179-187.

35. Bruijs PP, van der Schee EJ, Smout AJ, Akkemans LM, van Strien HL. Bedside system for cutaneous recording and analysis of gastric myoelectrical and impedance signals. Med Biol Eng Comput 1991; 29:609-615.

36. Stern RM, Koch KL, Stewart WR, Lindblad LM. Spectral analysis of tachygastria recorded during motion sickness. Gastroenterology 1987;92:92-97.

37. Mintchev MP, Bowes KL. Extracting quantitative information from digital electrogastrograms. Med Biol Eng Comput 1996;34:244248.

38. Marple SL. Digital spectral analysis with applications. Englewood Cliffs: Prentice-Hall 1987.
39. Chen J, McCallum RW. Gastric slow wave abnormalities in patients with gastroparesis. Am J Gastroenterol 1992;87:477-482.

40. van der Schee EJ, Grashuis JL. Running spectral analysis as an aid in the representation and interpretation of electrogastrographic signals. Med Biol Eng Comput 1987;25:57-62.

41. Mintchev MP, Kingma KJ, Bowes KL. Accuracy of coutaneous recordings of gastricelectrical activity. Gastroenterology 1993;104: 1273-1280.

42. Coleski R, Hasler WL. Directed endoscopic mucosal mapping of normal and dysrhythmic gastric slow waves in healthy humans. Neurogastroenterol Motil 2004;16:557-565.

43. Hamilton JW, Bellahsene BE, Reichelderfer M, Webster JG, Bass P. Human electrogastrograms: comparison of surface and mucosal recordings. Dig Dis Sci 1986;31:33-39.

44. Homma S, Satoh K, Matsuo H, et al. Electrogastrographic activity in patients who received proximal gastrectomy plus jejunal interposition or total gastrectomy plus jejunal interposition. J Smooth Muscle Res 2004;40:271-280.

45. Chen J, Richards RD, McCallum RW. Identification of gastric contractions from the cutaneous electrogastrogram. Am J Gastroenterol 1994;89:79-85.

46. Geldof H, van der Schee EJ, Grashuis JL. Electrogastrographic characteristics of interdigestive migrating complex in humans. Am J Physiol 1986;250(2 Pt 1):G165-G171.

47. van der Schee EJ, Grashuis JL. Contraction-related, low-frequency components in canine electrogastrographic signals. Am J Gastroenterol 1983;245:G470-G475.

48. Sha W, Pasricha PJ, Chen JD. Correlations among electrogastrogram, gastric dysmotility, and duodenal dysmotility in patients with functional dyspepsia. J Clin Gastroenterol 2009;43:716-722.

49. Parkman HP, Miller MA, Trate D, et al. Electrogastrography and gastric emptying scintigraphy are complementary for assessment of dyspepsia. J Clinical Gastroenterol 1997;24:214-219.

50. Cucchiara S, Salvia G, Borrelli O, et al. Gastric electrical dysrhythmias and delayed gastric emptying in gastroesophageal reflux disease. Am J Gastroenterol 1997;92:1103-1108.

51. Chen JD, Lin Z, McCallum RW. Noninvasive feature-based detection of delayed gastric emptying in humans using neural networks. IEEE Trans Biomed Eng 2000;47:409-412.

52. Liang L, Co E, Zhang M, Pineda J, Chen JD. Development of gastric slow waves in preterm infants measured by electrogastrography. Am J Physiol 1998;274(3 Pt 1):G503-G508.

53. Wang ZS, Elsenbruch S, Orr WC, Chen JD. Detection of gastric slow wave uncoupling from multi-channel electrogastrogram: validations and applications. Neurogastroenterol Motil 2003;15:457465.

54. Stern RM, Koch KL, Leibowitz HW, Lindblad IM, Shupert CL, Stewart WR. Tachygastria and motion sickness. Aviat Space Environ Med 1985;56:1074-1077.

55. Harm DL, Sandoz GR, Stern RM. Changes in gastric myoelectric activity during space flight. Dig Dis Sci 2002;47:1737-1745.

56. Stern RW, Vasey MW, Hu S, Koch KL. Effects of cold stress on gastric myoelectric activity. Neurogastroenterol Motil 1991;3:225228.

57. Qian L, Orr WC, Chen JD. Inhibitory reflexive effect of rectal distention on postprandial gastric myoelectrical activity. Dig Dis Sci 
2002;47:2473-2479.

58. Chen J, Song GQ, Yin J, Koothan T, Chen JD. Electroacupuncture improves impaired gastric motility and slow waves induced by rectal distension in dogs. Am J Physiol Gastrointest Liver Physiol 2008; 295:G614-G620

59. Liu J, Huang H, Xu X, Chen JD. Effects and possible mechanisms of acupuncture at ST36 on upper and lower abdominal symptoms induced by rectal distension in healthy volunteers. Am J Physiol Regul Integr Comp Physiol 2012;303:R209-R217.

60. Yin J, Chen JD. Gastrointestinal motility disorders and acupuncture. Auton Neurosci 2010;157:31-37.

61. Chen JD, Ke MY, Lin XM, Wang Z, Zhang M. Cisapride provides symptomatic relief in functional dyspepsia associated with gastric myoelectrical abnormality. Aliment Pharmacol Ther 2000;14:10411047.

62. Orr WC, Zhang M, McClanahan J, Sloan S, Chen JD. Gastric myoelectric activity in older adults treated with cisapride for gastro-oesophageal reflux disease. Aliment Pharmacol Ther 2000;14: 337-343.

63. Besherdas K, Leahy A, Mason I, Harbord M, Epstein O. The effect of Cisapride on dyspepsia symptoms and the electrogastrogram in patients with non-ulcer dyspepsia. Aliment Pharmacol Ther 1998;12: 755-759.

64. Chang CS, Lien HC, Yeh HZ, Poon SK, Tung CF, Chen GH. Effect of cisapride on gastric dysrhythmia and emptying of indigestible solids in type-II diabetic patients. Scand J Gastroenterol 1998;33:600-604.

65. DiBaise JK, Park FL, Lyden E, Brand RE, Brand RM. Effects of low doses of erythromycin on the 13C Spirulina platensis gastric emptying breath test and electrogastrogram: a controlled study in healthy volunteers. Am J Gastroenterol 2001;96:2041-2050.

66. Faure C, Wolff VP, Navarro J. Effect of meal and intravenous erythromycin on manometric and electrogastrographic measurements of gastric motor and electrical activity. Dig Dis Sci 2000;45:525-528.

67. Chen J, Yeaton P, McCallum RW. Effect of erythromycin on gastric myoelectrical activity in normal human subjects. Am J Physiol 1991;263(1 Pt 1):G24-G28.

68. Franzese A, Borrelli $\mathrm{O}$, Corrado $\mathrm{G}$, et al. Domperidone is more effective than cisapride in children with diabetic gastroparesis. Aliment Pharmacol Ther 2002;16:951-957.

69. Koch KL. Diabetic gastropathy: gastric neuromuscular dysfunction in diabetes mellitus: a review of symptoms, pathophysiology, and treatment. Dig Dis Sci 1999;44:1061-1075.

70. Koch KL, Stern RM, Stewart WR, Vasey MW. Gastric emptying and gastric myoelectrical activity in patients with diabetic gastroparesis: effect of long-term domperidone treatment. Am J Gastroenterol 1989;84:1069-1075.

71. Talley NJ, Camilleri M, Burton D, et al. Double-blind, randomized, placebo-controlled study to evaluate the effects of tegaserod on gastric motor, sensory and myoelectric function in healthy volunteers. Aliment Pharmacol Ther 2006;24:859-867.

72. Bortolotti M, Sarti P, Barara L, Brunelli F. Gastric myoelectric activity in patients with chronic idiopathic gastroparesis. Neurogastroenterol Motil 1990;2:104-108.

73. Rothstein RD, Alavi A, Reynolds JC. Electrogastrography in patients with gastroparesis and effect of long term cisaptide. Dig Dis Sci 1993;38:1518-1524.

74. You CH, Lee KY, Chey WY, Menguy R. Electrogastrographic study of patients with unexplained nausea, bloating and vomiting. Gastroenterology 1980;79:311-314.

75. Jednak MA, Shadigian EM, Kim MS, et al. Protein meals reduce nausea and gastric slow wave dysrhythmic activity in first trimester pregnancy. Am J Physiol 1999;277(4 Pt 1):G855-G861.

76. Walsh JW, Hasler WL, Nugent CE, Owyang C. Progesterone and estrogen are potential mediators of gastric slow-wave dysrhythmias in nausea of pregnancy. Am J Physiol 1996;270(3 Pt 1):G506-G514.

77. Riezzo G, Pezzolla F, Darconza G, Giorgio I. Gastric myoelectrical activity in the first trimester of pregnancy: a cutaneous electrogastrographic study. Am J Gastroenterol 1992;87:702-707.

78. Koch KL, Stern RM, Vasey M, Botti JJ, Creasy GW, Dwyer A. Gastric dysrhythmias and nausea of pregnancy. Dig Dis Sci 1990;35: 961-968.

79. Soykan I, Lin Z, Jones S, Chen J, McCallum RW. Gastric myoelectrical activity, gastric emptying and correlations with dyspepsia symptoms in patients with gastroesophageal reflux. J Investig Med 1997;45:483-487.

80. Jackson AL, Rashed H, Cardoso S, et al. Assessment of gastric electrical activity and autonomic function among diabetic and nondiabetic patients with symptoms of gastroesophageal reflux. Dig Dis Sic 2000:45:1727-1730.

81. Pfaffenbach B, Adamek RJ, Bartholomäus C, Wegener M. Gastric dysrhythmias and delayed gastric emptying in patients with functional dyspepsia. Dig Dis Sci 1997;42:2094-2099.

82. Lin X, Levanon D, Chen JD. Impaired postprandial gastric slow waves in patients with functional dyspepsia. Dig Dis Sci 1998; 43:1678-1684.

83. Lin Z, Eaker EY, Sarosiek I, McCallum RW. Gastric myoelectrical activity and gastric emptying in patients with functional dyspepsia. Am J Gastroenterol 1999;94:2384-2389.

84. Jung KT, Park H, Kim JH, et al. The relationship between gastric myoelectric activity and SCN5A mutation suggesting sodium channelopathy in patients with Brugada syndrome and functional dyspepsia - a pilot study. J Neurogastroenterol Motil 2012;18:58-63.

85. Leahy A, Besherdas K, Clayman C, Mason I, Epstein O. Abnormalities of the electrogastrogram in functional dyspepsia. Am J Gastroenterolol 1999;94:1023-1028. 